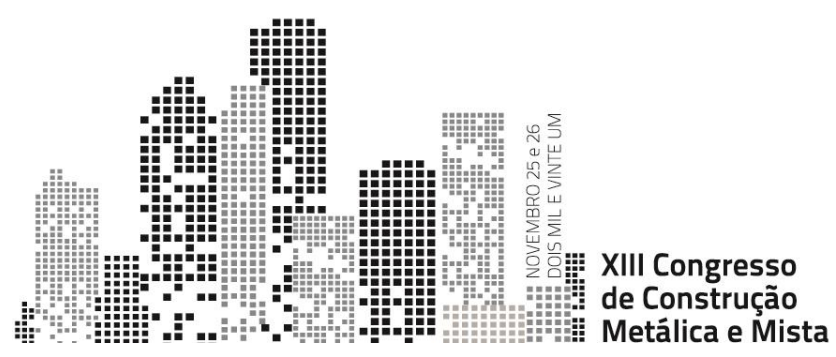

\title{
A NOVEL OPTIMISED INTER-LOCKING CONNECTION FOR STEEL MODULAR BUILDING SYSTEMS TO ENABLE REUSE
}

\author{
Corfar Dan-Adrian ${ }^{\mathrm{a}}$, Konstantinos Daniel Tsavdaridis ${ }^{\mathrm{b}}$ \\ ${ }^{\text {a,b }}$ School of Civil Engineering, Faculty of Engineering and Physical Sciences, University of \\ Leeds, Leeds, LS2 9JT, UK
}

\begin{abstract}
A new inter-module connection was developed, adopting structural topology optimisation (STO) and the inter-locking method of joining. The structural performance of the connection was assessed through a series of monotonic and cyclic FE analyses. Results revealed that the structural behaviour of the new connection was comparable to that of other inter-module joints in the literature, while managing to tackle their limitations by introducing both an easy-to-install and easy-to-disassemble configuration with promising opportunities for reuse, demonstrating that inter-locking joints can be worthy competitors for traditional means of attachment in the future of modular construction.
\end{abstract}

\section{Introduction}

Modular Building Systems (MBS) are a Modern Method of Construction (MMC) which adopts principles of Offsite Manufacturing (OSM) and Offsite Construction (OSC), delivering ready-to-install, fully finished structural modules; MBS enables reduced manufacturing costs due to standardisation and mass production, speed of onsite construction guaranteed by straightforward assembly sequences, and superior end-products delivered by better quality control and improved accuracy of production lines [1].

Due to its innate opportunities, this building technology has become increasingly popular in the high-rise construction sector too, where corner-supported systems made of hot-rolled steel are very popular due to superior rigidity and integrity as well as planning freedom due to opensided design (unobstructed walls between corner columns) [2]. 
In the structural anatomy of steel MBS, there are three types of connections (Fig. 1): intermodule, intra-module, and module-to-foundation connections. The former one is the tying system which ensures the structural integrity of the ensemble of modules, being the main influential factor for the overall stability and robustness of modular buildings. It provides connectivity in all three-dimensional directions by horizontally tying adjacent modules in two plan directions and vertically attaching stacked modules in order to allow for the transfer of in-plane forces.

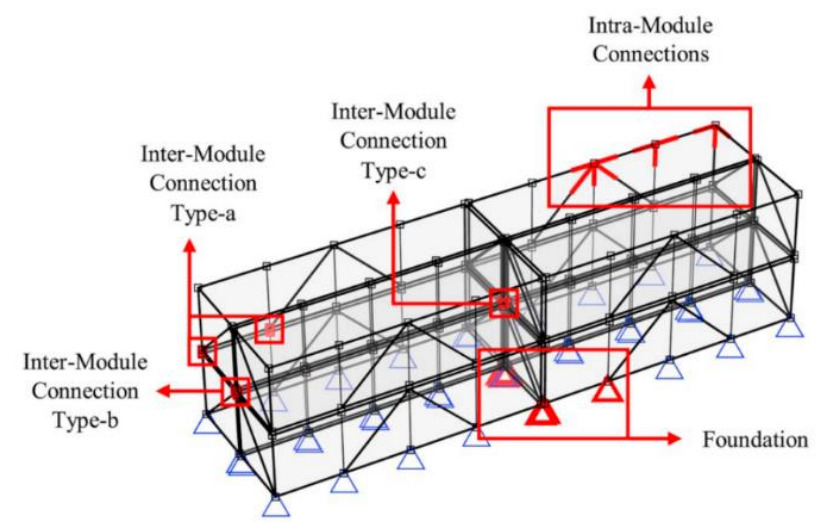

Fig. 1: Types of joints in MBS [3, p.6].

In the expansion of steel MBS in the high-rise construction sector, Srisangeerthanan et al. [3] linked the technical issues of MBS to poor performance of inter-module connections and proposed a comprehensive list of essential characteristics; among these, ease of assembly and ease of disassembly were deemed as most challenging in existing designs.

So far, existing inter-module connections have been influenced by conventional design methods, relying on bolts [4-8], welds [9], grout [10], or post-tensioning [11-12]. These methods often require laborious on-site tasks, hindering the demountability of MBS. Among these, one connection developed by Sharafi et al. [13] secures the continuity of steel MBS by interlocking strips with tongues and grooves, yet adhesives are indispensable for achieving effective uplift resistance.

Ferdous et al. [14] deemed the lack of reliable transfer paths through inter-module connections as detrimental in preventing the achievement of fully modular high-rise MBS. Moreover, the absence of design codes for steel modular construction leads to over-conservative designs which raise uncertainty about expected structural behaviour of modular buildings.

Consequently, topology optimisation (TO) can be a useful tool in the development process of structural connections, leading to promising designs. Structural topology optimisation (STO) has been employed for over two decades in industries like aerospace, automotive or manufacturing, while only in the last decade its utility has started to make a difference in the Architecture, Engineering and Construction (AEC) industry [15].

Numerous studies focused on the adoption of TO in early stages of structural projects as a design tool - reporting promising results for both structural systems [16, 17] and framing elements [18-20]. However, because of the one-off nature of construction projects, TO's biggest impact was made when applied for mass-produced components [21], like connection parts. In this regard, limited but valuable research was conducted about the design of metallic nodes for a variety of structures by employing STO [22, 23].

Therefore, this study developed a fastener-free, demountable inter-module connection by conducting an STO exploration of optimum material layouts and investigated its mechanical characteristics through nonlinear FEA. 


\section{The proposed inter-locking connection}

Based on a critical review of the literature of inter-module connections, two main ideas shaped the strategy of the new system: reliable structural behaviour through a TO-generated bearing component between modules and enhanced dismantling and reuse opportunities through "plug-in and slide" inter-locking joints. The development process was divided into three phases (Fig. 2) and the proposed connection system was illustrated in Fig. 3.

$\begin{aligned} & \text { Phase I: } \\ & \text { Traditional } \\ & \text { product } \\ & \text { design }\end{aligned}$
Phase II:
$\begin{aligned} & \text { TO of } \\ & \text { connector } \\ & \text { component }\end{aligned}$$\left\{\begin{array}{l}\begin{array}{l}\text { - devising the strategy and specific features of the new connection, such as: interlocking } \\ \text { joints, "plug-in and slide" features, attachment through beams, design for reuse } \\ \bullet \text { development of several raw designs (sketches) } \\ \bullet \text { exploration of proposed designs and further development of a suitable configuration }\end{array} \\ \text { Phase III: } \\ \begin{array}{l}\text { Performance } \\ \text { assessment }\end{array}\end{array}\left\{\begin{array}{l}\begin{array}{l}\text { establishing the specimen and purpose of the optimisation study } \\ \text { setting up the SIMP-based TO (design space, load cases, support conditions, objective } \\ \text { function, constraints, geometric/manufacturing restrictions) } \\ \text { post-processing of first results and interpretation of generated topologies in relation to } \\ \text { resisted load and correlated force path } \\ \text { heuristic investigation based on TO outcome and engineering intuition to determine a } \\ \text { viable generic design (morphogenesis process) }\end{array} \\ \begin{array}{l}\text { - determining static and seismic behaviour of proposed design by running FE stress } \\ \text { analyses }\end{array}\end{array}\right.\right.$

Fig. 2: Workflow of development process

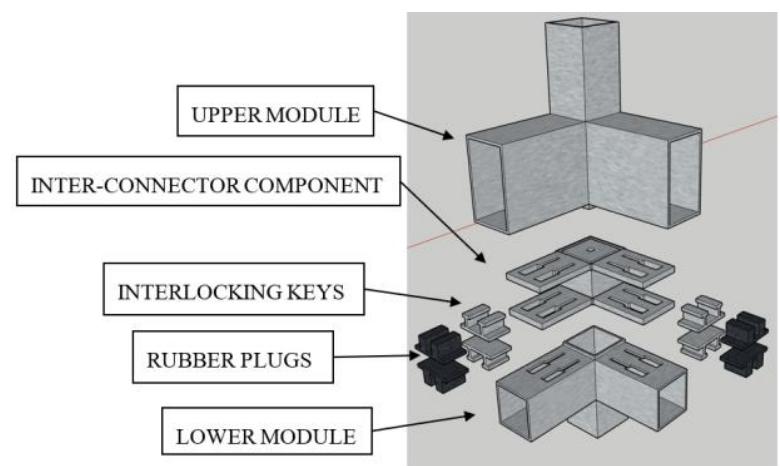

Fig. 3: Exploded view of proposed connection

The constitutive parts of the connection are shaped in accordance with their expected role in the load transfer mechanism. The inter-connector is expected to resist forces (axial, shearing, flexure, torsion) in all directions, being the paramount component of the joint. The L-shaped cover plates are designed to clasp the corners of modules, enhancing the strength of the connection regions. Grooves matching the cross-sections of posts are introduced to improve the shear resistance and to provide a straightforward load path for gravitational loads. The T-shaped plates ensure uplift resistance through the combined response of flanges in bending and webs in tension. The plugs are made of rubber to take advantage of material properties such as adhesion to metals, adequate tensile strength/compressive set, and long part lifespans [24-26]. Due to rubber's innate resilience, energy dissipation of the joint would be improved, while the plugs also act as seals, protecting the interlocking surface from moisture and harmful agents. The webs of the keys transfer horizontal shear forces, while the rubber plugs prevent the keys from sliding out. The symmetry of the system allows adaptability to external and internal configurations, while the fastener-free design enables straightforward assembly tasks without the need for special tooling and facilitates dismantling and reuse. Although the vertical gap between 
modules increases the building's height, it also provides better access for securing the joint, is able to accommodate building services, and the air barrier provides additional fire resistance and improves the acoustic performance of the modular structure [27].

\section{Topology optimisation of inter-connector part}

\subsection{Methodology}

During conceptual design of the inter-connector part, a 3D optimisation study was performed to investigate possible material layouts for the design space in Fig. $\mathbf{4 a}$ to determine an efficient configuration. In this study, the TO and morphogenesis focused exclusively on the column-like part of the connection to facilitate the interpretation of results, yet future studies may consider the connecting plates too for completeness. In the post-processing stage, several steps were implemented based on the Sectional Optimisation Method (SOM) developed by Tsavdaridis et al. [20], namely: studying various cross-sections of the optimised component imposed to a number of different loading and boundary conditions, plotting the overlaid X-rays to reveal internal configurations (dark areas require higher material concentration), and using engineering intuition to manually re-shape the newly found designs into a functional configuration.

\subsection{Optimisation study and modelling data}

The optimisation study was done using Abaqus/CAE's optimisation module TOSCA Structure [28]. Further post-processing of "noisy" topologies was done using Meshmixer [29].

General (sensitivity-based) topology optimisation is the default algorithm in TOSCA Structure and was preferred in the present study for its versatility in defining the task and for providing an overall robust solution. The optimisation goal was to generate the stiffest possible topologies within a specified design domain, under pre-determined sets of loading scenarios. As compliance (a measure of strain energy) is the inverse of stiffness, the objective function was set to minimise the compliance (maximise global stiffness); hence strain energy was chosen as the objective's design response while the volume of the design space was set as the design response. This approach delivered adequate solutions in previous studies [30-33].

Symmetry about all three axes was enforced to account for reverse loading directions, simulating all forces which occur in this joint configuration. The main load types can be seen in Fig. 4b/e. To ensure manufacturability member thicknesses were restricted to 10-15 mm.

A linear elastic steel material model was defined, with a density equal to $7850 \mathrm{~kg} / \mathrm{m}^{\wedge} 3$, Young's Modulus: $E=210 \mathrm{GPa}$ and Poisson's ratio: v $=0.3$, as specified in Eurocode 3 [34].

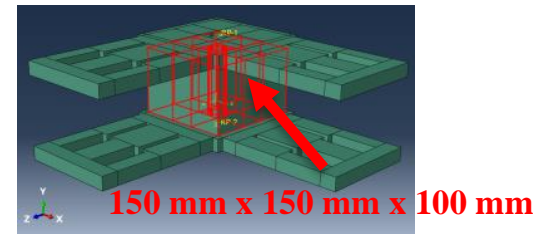

(a) Design space

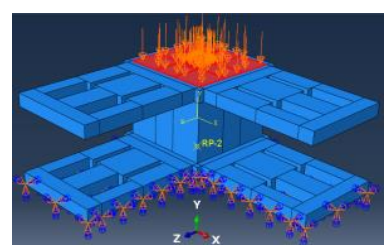

(b) Compression

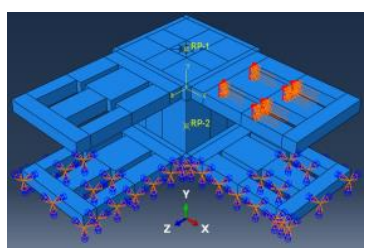

(c) Shear

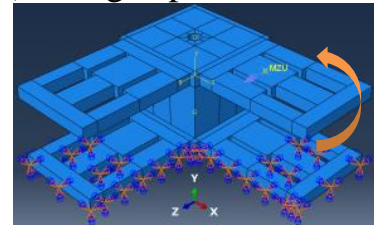

(d) Flexure

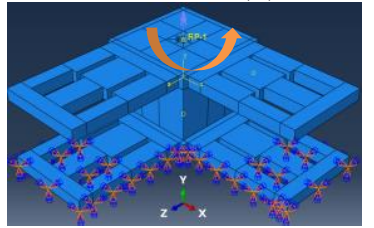

(e) Torsion

Fig. 4: Abaqus model and application of main load types 


\subsection{Optimisation results}

The following results were extracted from each trial using the default 0.3 iso-surface threshold, as it produced the clearest outputs. Effects of each load case was revealed by cutting representative sections at $25 \mathrm{~mm}, 50 \mathrm{~mm}$, and $75 \mathrm{~mm}$ of the design space's height (Fig. 5).

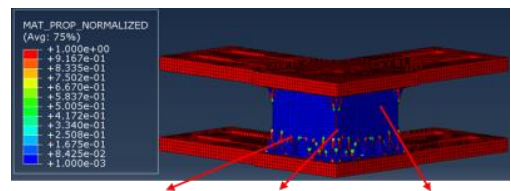

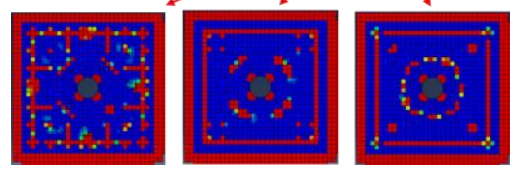

a) Compression/Tension
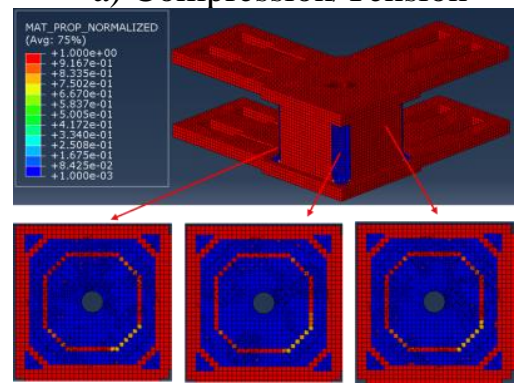

d) Torsion
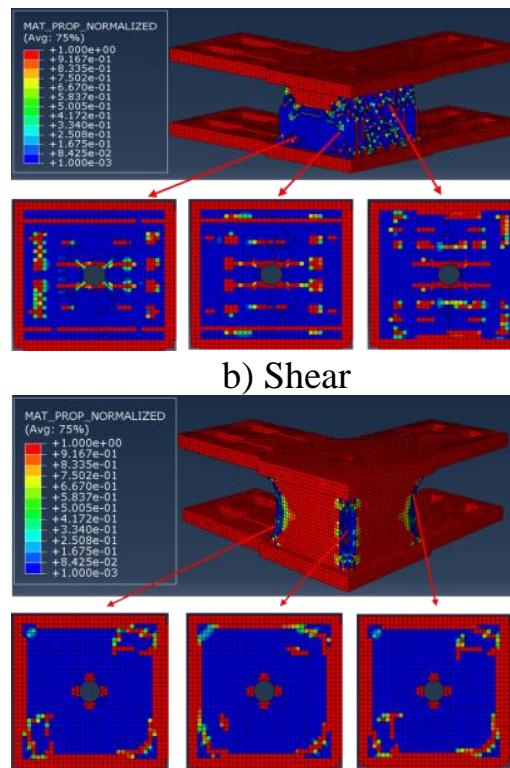

e) All loads (20\% volume)

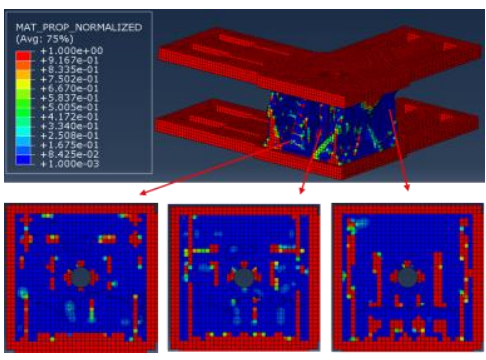

c) Flexure
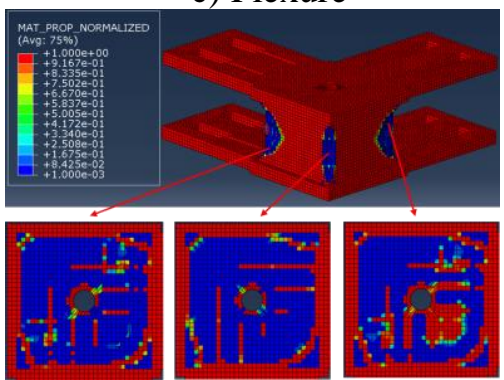

f) All loads (30\% volume)

Fig. 5: Material density plots $(0-$ void; 1 - solid $)$

In addition to the density plots, the transparent X-ray views in Fig. 6 complete the narrative of TO insights regarding the internal layouts. As anticipated, a great variety of "liquid lattice" structures with irregular struts connecting the upper and lower plates were formed.

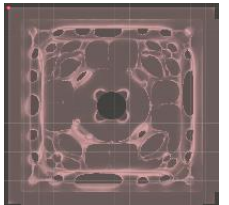

a)

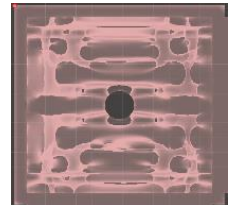

b) Shear

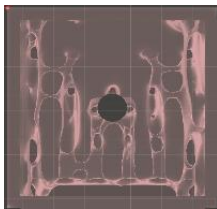

c) Flexure

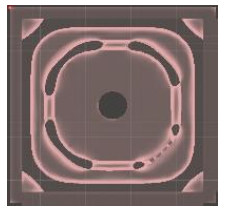

d) Torsion

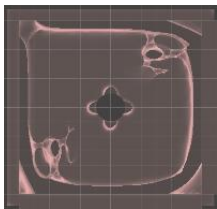

e) All loads (20\% volume)

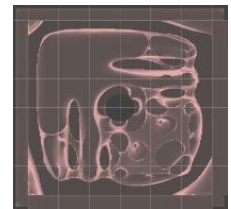

f) All loads (30\% volume)

Fig. 6: X-ray views of optimised designs

Stress paths of compressive, tensile, and torsional loads depicted the most regular material distributions with highly symmetric layouts (Fig. 5a/d), while shear and flexural loads generated less conventional configurations (Fig. $\mathbf{5 b} / \mathbf{c}$ ).

The outcome for the combined loading TO tasks (Fig. 5e/f) showed that when the final volume was more restrictive, material was mostly placed in the outer limits of the design space, highlighting these regions as critical in providing resistance to the studied actions.

\subsection{Morphogenesis process}

In this section, optimisation results from combined loading using $20 \%$ volume constraint were post-processed to produce two variations of the same morphology: one suitable for 3D printing (Fig. 8c) and another intended for subtractive manufacturing (Fig. 8d/e). 


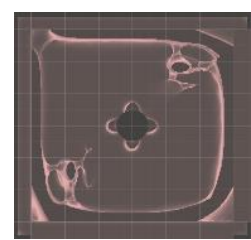

a)

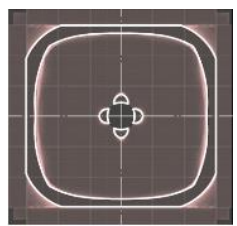

b)

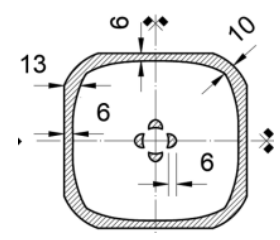

c)

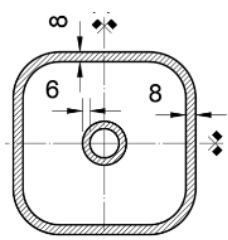

d)

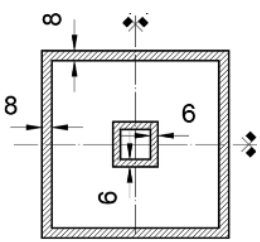

e)

Fig. 7: Morphogenesis process: a) unrefined topology, b) post-processed design, c) 3d-printed morphology, d) layout with curved walls, e) layout with straight walls

The morphology intended for 3D printing (Fig. 7b/c) was obtained by removing redundant structures and applying symmetry about both axes, while the outer profile of the conventional configuration was shaped into an $8 \mathrm{~mm}$ thick Square Hollow Section (SHS) with filleted corners, while the four struts were merged into a Circular Hollow Section (CHS) section. Tsavdaridis et al. [20] suggested that between profiles with straight and curved features, the former exhibited improved cross-sectional properties. Consequently, a layout with orthogonal walls was proposed in Fig. 7e.

While this TO investigation supported the adoption of complex 3D printable configurations, it also demonstrated that a classical SHS profile was already a highly efficient use of available space to resist the 10 load cases considered and could be ultimately regarded as a proof of concept for the purpose of this study. As a result, the design in Fig. 7e was further adopted in FEA studies presented in the next section.

\section{Numerical study of proposed inter-locking connection}

\subsection{Development of FE meso-scale model}

The software used in this study is Abaqus/CAE, employing the standard solver recommended for the nonlinear static stress analyses [35]. All FE modelling was done following the methodology from Khan and Yan [36], applying all three types of nonlinearities (geometric, material and boundary). The assembly modelled with 3D solid parts can be seen in Fig. 8a.

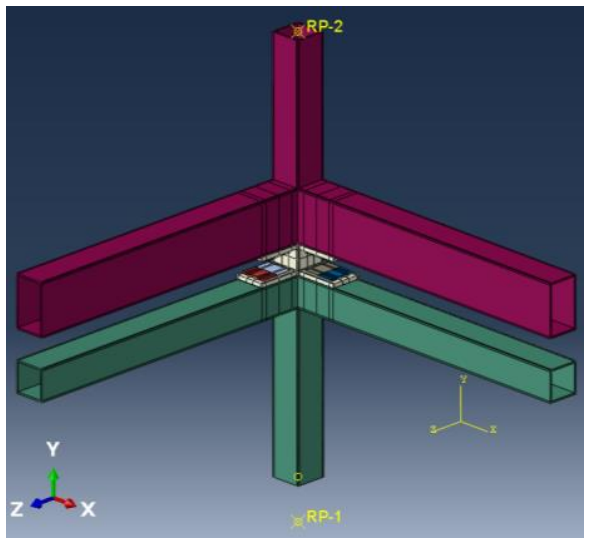

a)

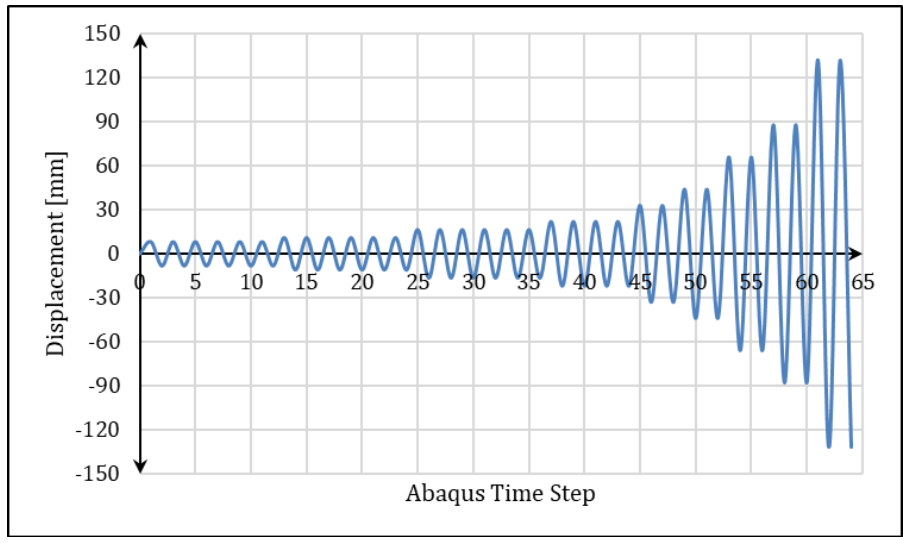

b)

Fig. 8: a) FEA meso-scale model assembly, b) FEMA/SAC loading history

All structural steel members were modelled with bi-linear material behaviour with kinematic hardening, using Young's Modulus: $E=210 \mathrm{GPa}$ and Poisson's ratio: $v=0.3$ for elasticity, while plasticity was introduced using the standard yield strength $f_{y}=355 \mathrm{~N} / \mathrm{mm}^{2}$ and ultimate tensile strength $f_{u}=490 \mathrm{~N} / \mathrm{mm}^{2}$ for $\mathrm{S} 355$ grade. 
As moderate compressive and shear strains were expected for the rubber parts, the NeoHookean form of hyperelasticity was adopted for its good accuracy [37], with a conventional Poisson's ratio of $v=0.4995$ for almost incompressible filled elastomers [38].

To capture the effect of gravitational actions, a compression load of $160 \mathrm{kN}(10 \%$ of the design resistance of the SHS cross-section) was applied and kept constant, while a lateral displacement of $100 \mathrm{~mm}$ was applied at the top of the upper column to study both monotonic and cyclic behaviours, investigating the working mechanism, failure modes, deformation capacity, and hysteretic response of the joint. For the cyclic testing, amplitude data (Fig. 8b) was defined according to FEMA 350 [39], using the FEMA/SAC protocol [40-42].

\subsection{Validation of FE modelling techniques}

The FEA procedures used herein were validated by comparisons with experimental and numerical results published in the literature. For the validation of static monotonic and quasi-static cyclic loading of an inter-module connection assembly, a numerical model based on the experimental setup used in Chen et al. [43] was developed (Fig. 9).
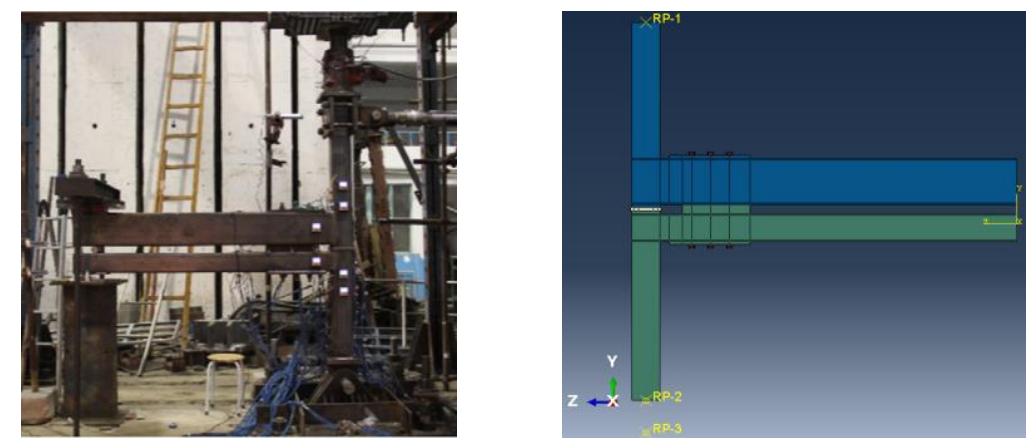

Fig. 9: Inter-module connection assembly: experimental setup vs. FE model

The lateral load-displacement curves of FEA models for specimens S1 and QS1 were compared with results from their experimental counterparts (Fig. 10). The FEA results are in satisfactory agreement with the monotonic response of the experimental results, with errors less than $10 \%$ throughout the curve. The hysteresis curves of the FEA specimen do not exhibit the same amount of strain hardening and load capacity as the experimental model in the reverse loading condition, yet the stiffness and overall shape of the curve match the experimental results. The presence of minor deviations can be justified given the numerical modelling simplifications and idealisation of material properties and experimental setup.
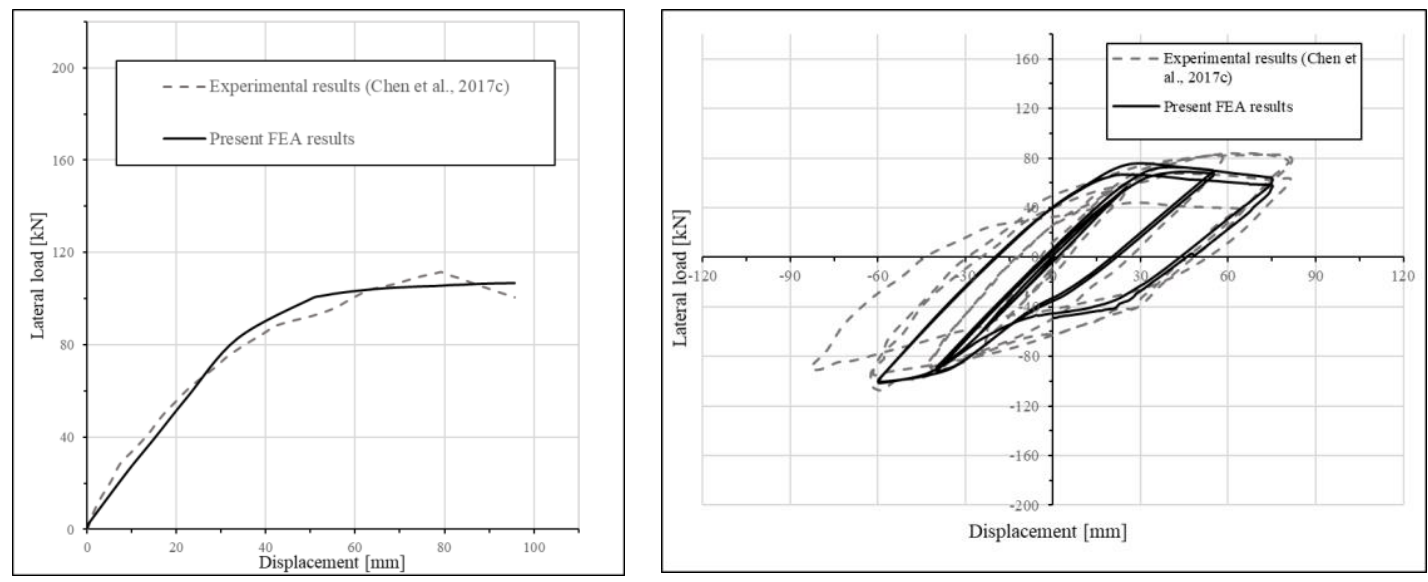

Fig. 10: Comparison of load-displacement curves: experimental vs. FEA 


\section{Mechanical behaviour of optimised inter-module connection}

The static behaviour of the connection was assessed by studying the load-displacement relationship and the von Mises stresses relative to the formation of plastic hinges in the members of the modular units. Since the lateral loading was displacement-controlled, the reaction force was tracked at the tip of the upper column to plot the monotonic curve (Fig. 11a).

The whole modular ensemble displayed linear elastic behaviour until the yield displacement reached approximately $30 \mathrm{~mm}\left(\Delta_{\mathrm{y}}\right)$ and a corresponding $64.98 \mathrm{kN}\left(P_{y}\right)$ yield load (point A). After this point, a slight decrease in the tangent stiffness occurred, signalling the start of the elastoplastic behaviour, followed by a second, more severe tangent stiffness change between points $\mathrm{B}$ and $\mathrm{C}$. As the lateral displacement reached $57.55 \mathrm{~mm}$ and the lateral force reached $90.38 \mathrm{kN}$, local inward and outward buckling of the lower post's outer wall (compression flange) occurred, causing a small drop in the lateral load capacity while a swift stress redistribution took place (Fig. 12c). Between point $C$ and D, steady hardening of the steel material was exhibited until the ultimate load capacity of $95.05 \mathrm{kN}\left(P_{u}\right)$ was reached at the end of the 100 $\mathrm{mm}\left(\Delta_{\mathrm{u}}\right)$ ultimate displacement.

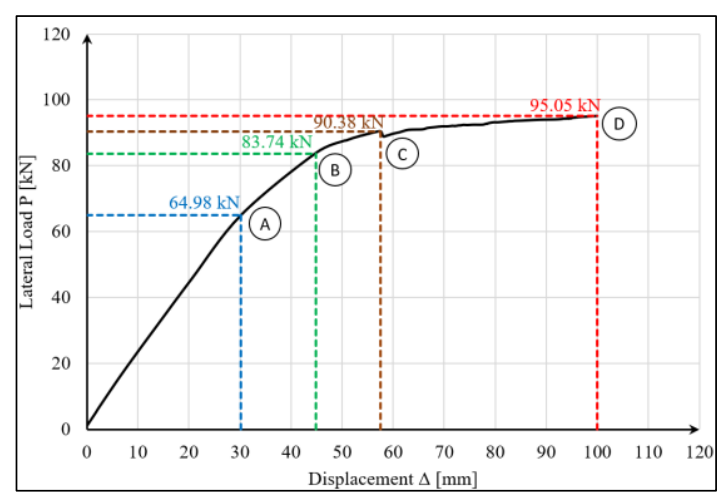

a)

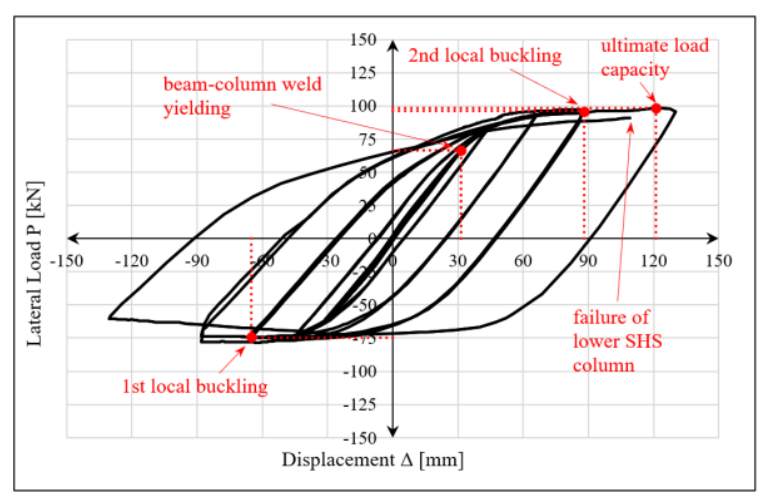

b)

Fig. 11: Lateral load-displacement responses: a) monotonic, b) hysteretic

After the initial yielding near the weld at point A (Fig. 12a), the plastic region propagated towards the upper beam-column joint (Fig. 12b), corresponding to the post-elastic stiffness change between points B-C, while the lower modular unit displayed increasingly higher stresses combined with local buckling in the compression flange of the column (Fig. 12c).

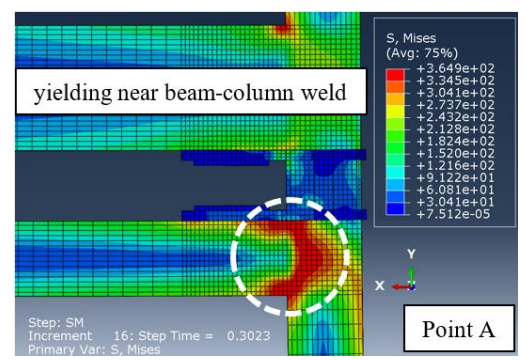

a)

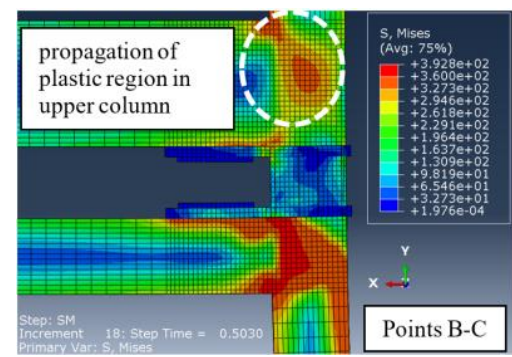

b)

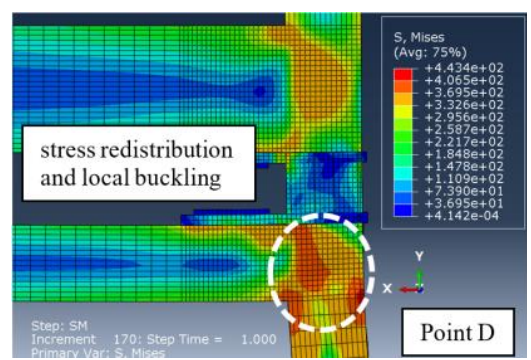

c)

Fig. 12: Evolution of von Mises stress under static monotonic lateral load

In Fig. 13, it was depicted that as the applied lateral displacement increased, the stress was moved to the wider and weaker regions of the holes. While the stress steadily intensified in these areas, it stabilised at around $370 \mathrm{MPa}$ (Fig. 13a) after reaching point $\mathrm{C}$ on the load-displacement curve, as a result of stress redistribution. 


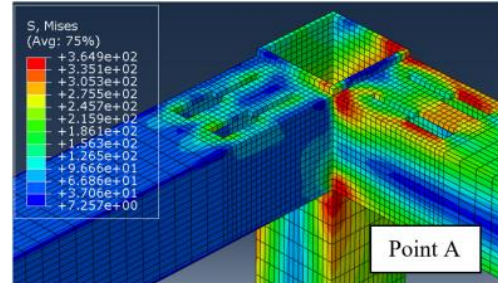

a)

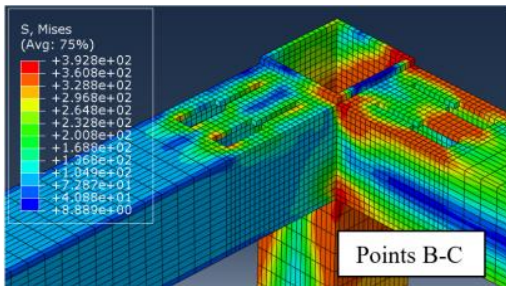

b)

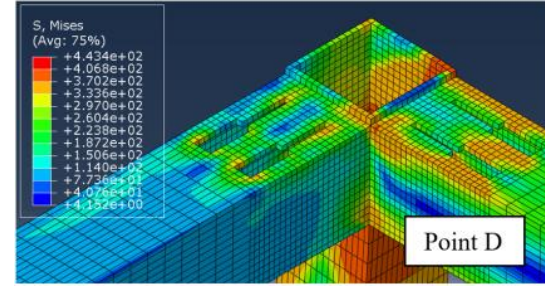

c)

Fig. 13: Influence of slotted holes on yielding sequence of modular unit

As the edges of the slotted holes came into contact with the T-stub keys, gaps opened between the inter-connector grooves and the walls of the SHS post (Fig. 14a), while the "L"plates of the inter-connector exhibited out-of-plane bending against the compressed rubber stoppers. The contour plots in Fig. 14b showed that the hyperelastic material model responded appropriately as the rubber plugs were being compressed against the slotted holes in the beams, resisting displacement in the direction of the lateral load.

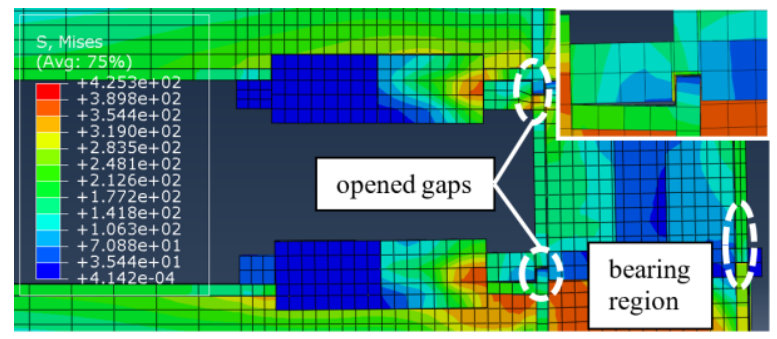

a)

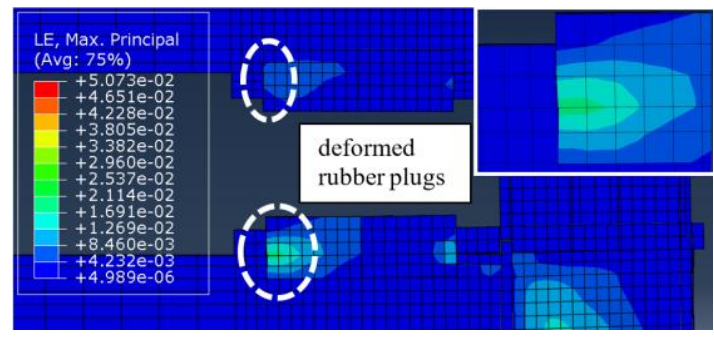

b)

Fig. 14: Cross-section view: a) Mises contours, b) logarithmic strain (LE)

As a result of the cyclic loading procedure, the hysteretic curve (Fig. 11b) identified characteristics of the seismic performance of the proposed connection. The overall response of the interlocking joint was comparable to that of conventional inter-modular connections.

During the low-frequency cycles the specimen exhibited linear elastic response, being in good agreement with the static results, as yielding near the beam-column weld (Fig. 15a) was registered at the end of the second cycle of $+\Delta_{y}$. First signs of local damage were seen at the end of the first cycle of $-2 \Delta_{\mathrm{y}}(-66 \mathrm{~mm})$, when the compressed inner flange of the lower SHS column buckled (Fig. 15b), followed by a second local failure of the outer SHS flange, as the lateral displacement reached the first cycle of $+2.67 \Delta_{\mathrm{y}}(+88 \mathrm{~mm})$ and the lateral load of 66.35 $\mathrm{kN}$. An ultimate load capacity $P_{u}$ of $98.1 \mathrm{kN}$ was measured right before the completion of the first $+4 \Delta_{\mathrm{y}}(+132 \mathrm{~mm})$ cycle. The simulation stopped at a lateral displacement of $+\Delta_{\mathrm{f}}$ equal to $+109 \mathrm{~mm}$ and a failure load $P_{f}$ equal to $90.8 \mathrm{kN}$, failing to complete the second cycle of $+4 \Delta_{\mathrm{y}}$ $(+132 \mathrm{~mm})$ due to cumulative plastic deformation which withstood by the lower SHS column, which displayed clear signs of cross-sectional failure and strength degradation (Fig. 15c).

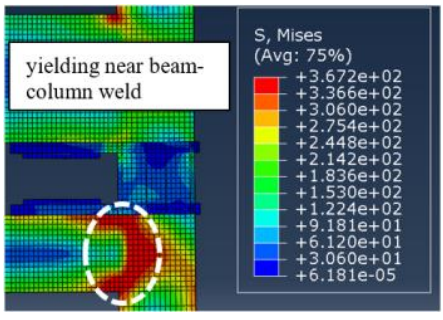

a)

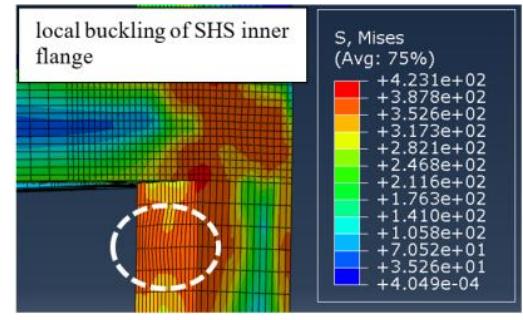

b)

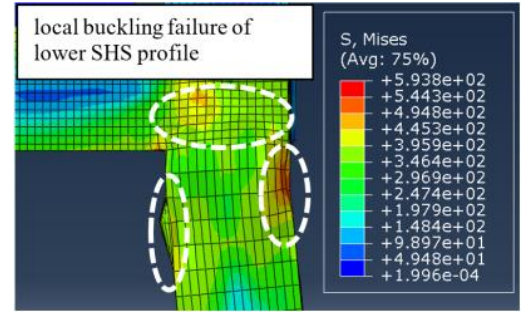

c)

Fig. 15: Damage progression and failure modes under cyclic loading 
The wide and round shape of the hysteresis loop (Fig. 16a) generally indicated promising energy dissipation capabilities, supporting the efficiency of the proposed connection. The envelope curve reflected the joint's load-bearing capacity, as the curve flattened rapidly in the post-yielding stage of the positive loading direction, while the negative cycles showed distinctive signs of strength degradation highlighted by the descending stage of the curve.

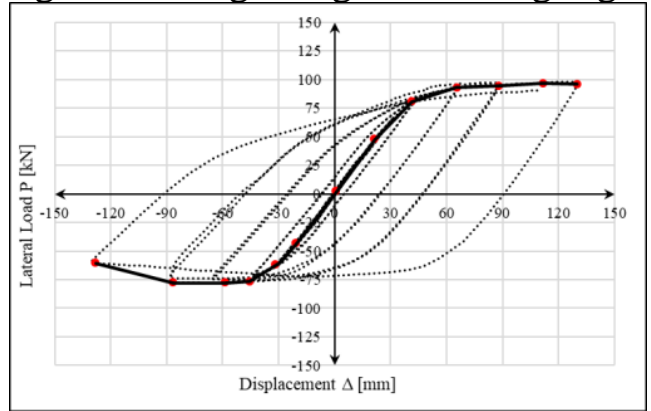

a)

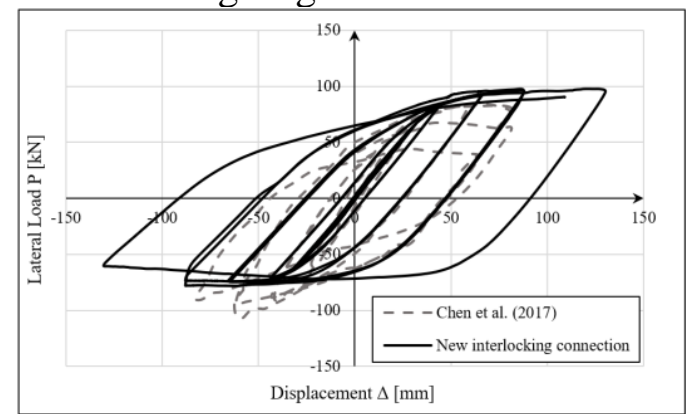

b)

Fig. 16: a) Envelope curve, b) Comparison of cyclic response with existing inter-module connection

Furthermore, essential seismic characteristics were obtained from the hysteresis loop and listed in Table 1 . The ductility ratio $\mu\left(\Delta_{\mathrm{u}} / \Delta_{\mathrm{y}}\right)$ showcased the capability of the connection to deform plastically without losing its strength and was calculated according to Chen et al. [43], where $\Delta_{\mathrm{u}}$ was the displacement at ultimate load capacity and $\Delta_{\mathrm{y}}$ was the yielding displacement. The equivalent damping coefficient $h_{e}$ was calculated using the areas enclosed by the hysteresis curve [44] to measure the energy dissipation of the connection.

Table 1: Mechanical factors related to seismic performance

\begin{tabular}{ccccccccc}
\hline $\begin{array}{c}\text { Loading } \\
\text { direction }\end{array}$ & $\begin{array}{c}\Delta_{\mathrm{y}} \\
(\mathrm{mm})\end{array}$ & $\begin{array}{c}\Delta_{\mathrm{u}} \\
(\mathrm{mm})\end{array}$ & $\mathrm{P}_{\mathrm{y}}(\mathrm{kN})$ & $\mathrm{P}_{\mathrm{u}}(\mathrm{kN})$ & $\mathrm{P}_{\max }(\mathrm{kN})$ & $\begin{array}{c}\mathrm{P}_{\max } / \\
\mathrm{P}_{\mathrm{y}}\end{array}$ & $\mu$ & $\mathrm{h}_{\mathrm{e}}$ \\
\hline$(+)$ & 31.35 & 130.07 & 66.35 & 95.84 & 98.1 & 1.478 & 4.15 & \\
$(-)$ & 31.45 & 130.41 & 61.93 & 60.5 & 78.27 & 1.264 & 4.14 & 0.413 \\
\hline
\end{tabular}

The displacement ductility factors were almost identical in both the positive and negative cycles and their values were slightly higher than those from literature [43], revealing superior plastic deformation ability (Fig. 16b). Similarly, the equivalent damping coefficient was also comparable to that of Chen et al.'s [43] unstiffened specimens, exhibiting satisfactory energy absorption.

\section{Concluding remarks}

The main conclusions are herein synopsised:

1. The TO exploration was insightful in the development of a safe and efficient inter-connector, supporting its use in the conceptual design of future inter-module connections.

2. The mechanical behaviour of the proposed connection demonstrated that fastener-free inter-locking joints provide comparable seismic performance to conventional designs.

3. None of the connection's components showed signs of premature failure, demonstrating a robust structural response which supports its opportunities for reuse.

4. The stress concentrations around slotted holes suggest the need for further strengthening these regions, while the buckling of the SHS columns calls for additional stiffeners. 


\section{References}

[1] Goodier, C. and A. Gibb, Future opportunities for offsite in the UK. Construction Management and Economics, 2007. 25(6): p. 585-595.

[2] Lawson, R.M., R.G. Ogden, and C. Goodier, Design in Modular Construction. 2014, Oxon: CRC Press.

[3] Srisangeerthanan, S., et al., Review of performance requirements for inter-module connections in multi-story modular buildings. Journal of Building Engineering, 2020. 28.

[4] Liu, X.C., et al., Performance analysis and design of bolted connections in modularized prefabricated steel structures. Journal of Constructional Steel Research, 2017. 133: p. 360-373.

[5] Dhanapal, J., et al., Behavior of thin-walled beam-column modular connection subject to bending load. Thin-Walled Structures, 2020. 149.

[6] Chen, Z., et al., Tensile and shear performance of rotary inter-module connection for modular steel buildings. Journal of Constructional Steel Research, 2020. 175.

[7] Sendanayake, S.V., et al., Enhancing the lateral performance of modular buildings through innovative inter-modular connections. Structures, 2021. 29: p. 167-184.

[8] Lacey, A.W., et al., New interlocking inter-module connection for modular steel buildings: Experimental and numerical studies. Engineering Structures, 2019. 198.

[9] Annan, C.D., M.A. Youssef, and M.H. El Naggar, Experimental evaluation of the seismic performance of modular steel-braced frames. Engineering Structures, 2009. 31(7): p. 1435-1446.

[10] Dai, Z., et al., Experimental study of grouted sleeve connections under bending for steel modular buildings. Engineering Structures, 2021. 243.

[11] Lacey, A.W., et al., Shear behaviour of post-tensioned inter-module connection for modular steel buildings. Journal of Constructional Steel Research, 2019. 162.

[12] Sanches, R., O. Mercan, and B. Roberts, Experimental investigations of vertical post-tensioned connection for modular steel structures. Engineering Structures, 2018. 175: p. 776-789.

[13] Sharafi, P., et al., Interlocking system for enhancing the integrity of multi-storey modular buildings. Automation in Construction, 2018. 85: p. 263-272.

[14] Ferdous, W., et al., New advancements, challenges and opportunities of multi-storey modular buildings - A state-of-the-art review. Engineering Structures, 2019. 183: p. 883-893.

[15] Sotiropoulos, S., G. Kazakis, and N.D. Lagaros, Conceptual design of structural systems based on topology optimization and prefabricated components. Computers \& Structures, 2020. 226.

[16] Kingman, J.J., K.D. Tsavdaridis, and V.V. Toropov, Applications of Topology Optimization in Structural Engineering : High - Rise Buildings and Steel Components. Jordan Journal of Civil Engineering, 2015. 9(3): p. 335-357.

[17] Dapogny, C., et al., Geometric constraints for shape and topology optimization in architectural design. Computational Mechanics, 2017. 59(6): p. 933-965.

[18] Tsavdaridis, K.D., J.J. Kingman, and V.V. Toropov, Application of structural topology optimisation to perforated steel beams. Computers \& Structures, 2015. 158: p. 108-123.

[19] Tsavdaridis, K.D., et al., Novel Optimised Structural Aluminium Cross-Sections Towards 3D Printing, in Industrializing Additive Manufacturing - Proceedings of Additive Manufacturing in Products and Applications - AMPA2017. 2018. p. 34-46.

[20] Tsavdaridis, K.D., et al., Application of structural topology optimisation in aluminium cross-sectional design. Thin-Walled Structures, 2019. 139: p. 372-388.

[21] Belegundu, A.D. and T.R. Chandrupatla, Optimization Concepts and Applications in Engineering. 3rd ed. 2019, Cambridge: Cambridge University Press.

[22] Galjaard, S., et al. Optimizing Structural Building Elements in Metal by using Additive Manufacturing. in International Association for Shell and Spatial Structures (IASS) Symposium 2015. Amsterdam, The Netherlands.

[23] Abdelwahab, M.M. and K.D. Tsavdaridis. Optimised 3D Printed Metallic Node-Connections for Reticulated Structures. in 9th International Conference on Steel and Aluminium Structures (ICSAS19). 2019. Bradford, UK: Independent Publishing Network.

[24] Cook, R.A. and D. Allen, Stiffness Evaluation Of Neoprene Bearing Pads Under Long-Term Loads. 2009, University of Florida. 
[25] Roth, F.L., R.L. Driscoll, and W.L. Holt, Frictional Properties of Rubber. Journal of Research of the National Bureau of Standards, 1942. 28(April): p. 439-462.

[26] Low, K.O. and W.C. Teo, Characteristics of SBR, Neoprene and EPDM compounds in a singlepass pendulum scratch. Tribology International, 2012. 54: p. 9-16.

[27] Lawson, R.M., R.G. Ogden, and R. Bergin, Application of Modular Construction in High-Rise Buildings. Journal of Architectural Engineering, 2012. 18(2): p. 148-154.

[28] Dassault Systèmes SIMULIA Corp. TOSCA Structure. Optimize with Abaqus, Ansys, or MSC Nastran. 2019.

[29] Autodesk Inc. Meshmixer. 2018.

[30] Anand, K. and A. Misra, Topology Optimization and Structural Analysis of Continuous Linear Elastic Structures using Optimality Criterion Approach in ANSYS. International Journal of Innovative Research in Science, Engineering and Technology, 2015. 4(6).

[31] Grekavicius, L., et al., Novel Morphologies of Aluminium Cross-Sections through Structural Topology Optimization Techniques. Key Engineering Materials, 2016. 710: p. 321-326.

[32] Saleem, W., A. Ahmed, and A.A. Taimoor, Optimal design of ribbed-stiffened machined structures through material layout optimization. Journal of Advanced Mechanical Design, Systems, and Manufacturing, 2017. 11(2): p. JAMDSM0014-JAMDSM0014.

[33] Saadlaoui, Y., et al., Topology optimization and additive manufacturing: Comparison of conception methods using industrial codes. Journal of Manufacturing Systems, 2017. 43: p. 178-186.

[34] BSI, Eurocode 3: Design of steel structures - Part 1-1: General rules and rules for buildings. 2015, BSI: London.

[35] Dassault Systèmes SIMULIA Corp. Abaqus Analysis User's Manual. 2019.

[36] Khan, K. and J.-B. Yan, Finite Element Analysis on Seismic Behaviour of Novel Joint in Prefabricated Modular Steel Building. International Journal of Steel Structures, 2020. 20(3): p. 752-765.

[37] Kim, B., et al., A comparison among Neo-Hookean model, Mooney-Rivlin model, and Ogden model for chloroprene rubber. International Journal of Precision Engineering and Manufacturing, 2012. 13(5): p. 759-764.

[38] Dassault Systèmes SIMULIA Corp. SIMULIA Abaqus 2019 Documentation. 2019.

[39] FEMA, Recommended Seismic Design Criteria for New Steel Moment-Frame Buildings. 2000, FEMA.

[40] Krawinkler, H., Loading Histories For Cyclic Tests In Support Of Performance Assessment Of Structural Components. 2009.

[41] Krawinkler, H., et al., Guidelines for Cyclic Seismic Testing of Components of Steel Structures. 1992: Applied Technology Council.

[42] Krawinkler, H. and S.A.C.J. Venture, Loading histories for seismic performance testing of SMRF components and assemblies. 2002, [Sacramento, Calif.]: SAC Joint Venture.

[43] Chen, Z., et al., Experimental study of an innovative modular steel building connection. Journal of Constructional Steel Research, 2017. 139: p. 69-82

[44] Qin, Y., et al., Experimental seismic behavior of through-diaphragm connections to concretefilled rectangular steel tubular columns. Journal of Constructional Steel Research, 2014. 93: p. $32-43$ 